\title{
Reference Values of Maximal Oxygen Uptake for Polish Rowers
}

\author{
by \\ Andrzej Klusiewicz 1, Michał Starczewski1, Maria Ładyga1, Barbara Długołęcka², \\ Wojciech Braksator ${ }^{3}$, Artur Mamcarz ${ }^{4}$, Dariusz Sitkowski ${ }^{1}$
}

The aim of this study was to characterize changes in maximal oxygen uptake over several years and to elaborate current reference values of this index based on determinations carried out in large and representative groups of top Polish rowers. For this study 81 female and 159 male rowers from the sub-junior to senior categories were recruited from the Polish National Team and its direct backup. All the subjects performed an incremental exercise test on a rowing ergometer. During the test maximal oxygen uptake was measured with the BxB method. The calculated reference values for elite Polish junior and U23 rowers allowed to evaluate the athletes' fitness level against the respective reference group and may aid the coach in controlling the training process. Mean values of VO2max achieved by members of the top Polish rowing crews who over the last five years competed in the Olympic Games or World Championships were also presented. The results of the research on the "trainability" of the maximal oxygen uptake may lead to a conclusion that the growth rate of the index is larger in case of high-level athletes and that the index (in absolute values) increases significantly between the age of 19-22 years (U23 category).

Key words: Polish rowers, VO2max, reference values.

\section{Introduction}

For several dozen years maximal oxygen uptake (VO2max) has been regarded as the primary physiological index used for the assessment of the organism's cardio-pulmonary fitness and predisposition towards success in endurance sports (Hue et al., 2000; Klusiewicz et al., 1999; Legaz-Arresea et al., 2007; Losnegard and Hallén, 2014; Millet et al., 2003; Suriano and Bishop, 2010; Yagüe et al., 2013). Indeed, a strong relationship between the place taken in international regattas and $\mathrm{VO} 2 \mathrm{max}$ values achieved by the athletes has been demonstrated (Secher et al., 1982). Currently, based on longterm observations of an outstanding senior rower, a medal winner at seven Olympic Games and
World Championships, a correlation has been suggested between competition results and the capacity to maximally uptake high amounts of oxygen (about $6.0 \mathrm{l} / \mathrm{min}$ ) and the peak power attained in the incremental exercise test on a rowing ergometer (Lacour et al., 2009). The athlete's capability to withstand heavy training workload until the age of 32 was an additional factor in this case. Another study (Mikulic, 2011) showed that within a five-year observation period, starting from the age of 16 years, the world-class rowers demonstrated a systematic and significant increase $(26 \%)$ in the maximal oxygen uptake up to the level of about $6.6 \mathrm{l} / \mathrm{min}$ (i.e. $70 \mathrm{ml} / \mathrm{kg} / \mathrm{min}$ ).

\footnotetext{
1 - Department of Physiology, Institute of Sport, Warsaw, Poland.

2 - Department of Physiology and Biochemistry, The Josef Pilsudski University of Physical Education in Warsaw, Faculty of Physical Education and Sport in Biala Podlaska, Poland.

3 - Department of Cardiology, Hypertension and Internal Diseases, Medical University of Warsaw, Warsaw, Poland.

4 - III Department of Cardiology and Internal Diseases, Medical University of Warsaw, Warsaw, Poland.
} 
We attempted to describe multi-year changes in maximal oxygen uptake, and we elaborated up-to-date reference values of this index based on studies of large and representative groups of Polish elite rowers.

\section{Material and Methods}

The cross-sectional studies have been conducted over the last four years on numerous groups of female $(n=81)$ and male $(n=159)$ rowers from the sub-junior to senior categories of the Polish National Team and its direct back-up. Approval from the Research Ethics Committee of the Institute of Sport in Warsaw had been granted before the commencement of the tests and informed written consent to participate in the study had been obtained from all subjects.

All the participants performed an incremental exercise test until exhaustion on the Concept II rowing ergometer at the workloads shown in Table 1. The test consisted of threeminute exercise bouts separated by $30 \mathrm{~s}$ rest periods (Klusiewicz, 2005).

During the exercise test, the HR was continuously monitored with the use of a Polar S610i recorder (Polar Electro Oy, Finland). The respiratory exchange indices were measured with the $B \times B$ method using the MetaLyser $3 B$ and MetaMax 3B devices (Cortex, Germany). Three minutes after the incremental exercise bouts until exhaustion, blood samples were collected for determination of the lactate concentration with the use of the Super GL 2 (Dr Müller, Germany) devices.

Maximal oxygen uptake $\left(\mathrm{VO}_{2 \max }\right)$ was defined as the highest amount of oxygen consumed by the athlete's organism during one minute of the test. The maximal intensity exercise necessary for estimation of $\mathrm{VO}_{2 m a x}$ was defined by the following criteria: the $\mathrm{VO}_{2}$ plateauing with increasing workload, the post-exercise blood lactate concentration $>8 \mathrm{mmol} / \mathrm{l}$, the Respiratory Exchange Ratio (RER) $>1.1$ and the attainment of the age-adjusted maximal heart rate expressed as HRmax $=220$ - age of the subject. If at least two of the above criteria were met during the exercise, the attained effort and oxygen uptake were regarded as maximal.

For statistical analysis of the results means (x) and standard deviations (SD) of the examined parameters $(x)$ were calculated. The Shapiro-Wilk test was used to check if the distribution of examined variables was normal. To compare the results, one-way analysis of variance (ANOVA) was used. For detailed comparisons (between groups) the post-hoc Tukey's test for unequal samples was utilised. The level of statistical significance was set at $p<0.05$. For all the calculations and statistical analyses of the results the Statistica v.8 (StatSoft) software was used.

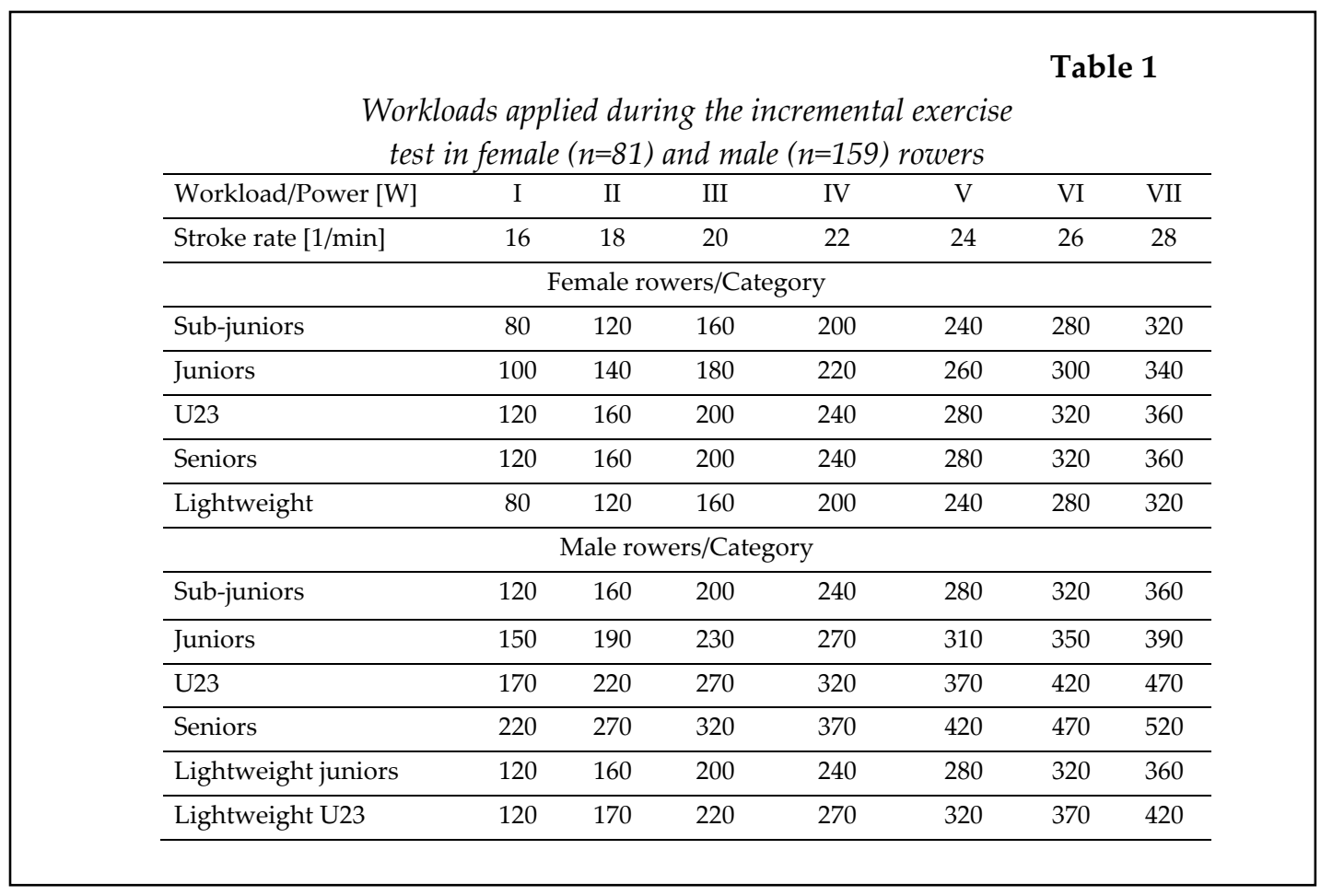


Table 2

Reference values of maximal oxygen uptake $\left(V_{2} \mathrm{z}_{\text {max }}\right)$ defined for the examined categories of female $(n=81)$ and male $(n=159)$ rowers

\begin{tabular}{|c|c|c|c|c|c|c|}
\hline & \multicolumn{3}{|c|}{$\mathrm{VO}_{2 \max }[1 / \mathrm{min}]$} & \multicolumn{3}{|c|}{$\mathrm{VO}_{2 \max }[\mathrm{ml} / \mathrm{kg} / \mathrm{min}]$} \\
\hline Assessment & Low & Average & High & Low & Average & High \\
\hline \multicolumn{7}{|l|}{ Category } \\
\hline \multicolumn{7}{|c|}{ Females } \\
\hline FSJ $(n=9)$ & $3.0 \leq$ & $3.0-3.3$ & $\geq 3.3$ & $45.1 \leq$ & $45.1-49.1$ & $\geq 49.1$ \\
\hline $\mathrm{FJ}(\mathrm{n}=39)$ & $3.3 \leq$ & $3.3-3.6$ & $\geq 3.6$ & $47.0 \leq$ & $47.0-51.5$ & $\geq 51.5$ \\
\hline FY $(n=24)$ & $3.5 \leq$ & $3.5-3.8$ & $\geq 3.8$ & $49.5 \leq$ & $49.5-54.9$ & $\geq 54.9$ \\
\hline FYLW $(n=9)$ & $3.2 \leq$ & $3.2-3.5$ & $\geq 3.5$ & $55.6 \leq$ & $55.6-58.3$ & $\geq 58.3$ \\
\hline \multicolumn{7}{|c|}{ Males } \\
\hline MSJ $(n=11)$ & $4.6 \leq$ & $4.6-5.0$ & $\geq 5.0$ & $59.3 \leq$ & $59.3-64.1$ & $\geq 64.1$ \\
\hline $\mathrm{MJ}(\mathrm{n}=52)$ & $4.7 \leq$ & $4.7-5.3$ & $\geq 5.3$ & $58.8 \leq$ & $58.8-64.5$ & $\geq 64.5$ \\
\hline$M Y(n=58)$ & $5.3 \leq$ & $5.3-5.8$ & $\geq 5.8$ & $59.8 \leq$ & $59.8-64.8$ & $\geq 64.8$ \\
\hline MJLW (n=10) & $4.3 \leq$ & $4.3-4.8$ & $\geq 4.8$ & $62.0 \leq$ & $62.0-67.4$ & $\geq 67.4$ \\
\hline MYLW (n=32) & $4.7 \leq$ & $4.7-5.1$ & $\geq 5.1$ & $65.0 \leq$ & $65.0-70.0$ & $\geq 70.0$ \\
\hline
\end{tabular}

Parameter level: low $<(x-0.5 S D)$, average $=(x \pm 0.5 S D)$, high $>(x+0.5 S D)$ FSJ-female sub-juniors, FJ-female juniors, FY-female U23,

FYLW - female U23 lightweight

MSJ - male sub-juniors, $M J$ - male juniors, $M Y$ - male U23, MJLW-male junior lightweight, MYLW-male U23 lightweight

Table 3

The highest mean values of maximal oxygen uptakes $\left(\mathrm{VO}_{2 \max }\right)$ attained by the top Polish rowing crews who over the last five years competed in the Olympic Games (O.G.) and World Championships (W.Ch.)

\begin{tabular}{ccccc}
\hline Crew & Regatta & Place taken & \multicolumn{2}{c}{$\mathrm{VO}_{2 \max }$} \\
& & & {$[\mathrm{ml} / \mathrm{min}]$} & {$[\mathrm{kg} / \mathrm{min}]$} \\
\hline \multirow{2}{*}{ 2xKA } & O.G. 2012 & III & & \\
\hline \multirow{2}{*}{ WxMA } & W.Ch. 2010 & III & $4.45 \pm 0.11$ & $63.3 \pm 1.8$ \\
\hline & O.G. 2008 & I & & \\
$4-\mathrm{ML}^{*}$ & W.Ch. 2009 & I & $6.08 \pm 0.65$ & $64.9 \pm 6.1$ \\
\hline
\end{tabular}

$2 x K A-a$ women double scull, $4 x M A-a$ men quadruple scull, 4-ML - a men lightweight coxless four

* different members of the crew in 2008 and 2009 


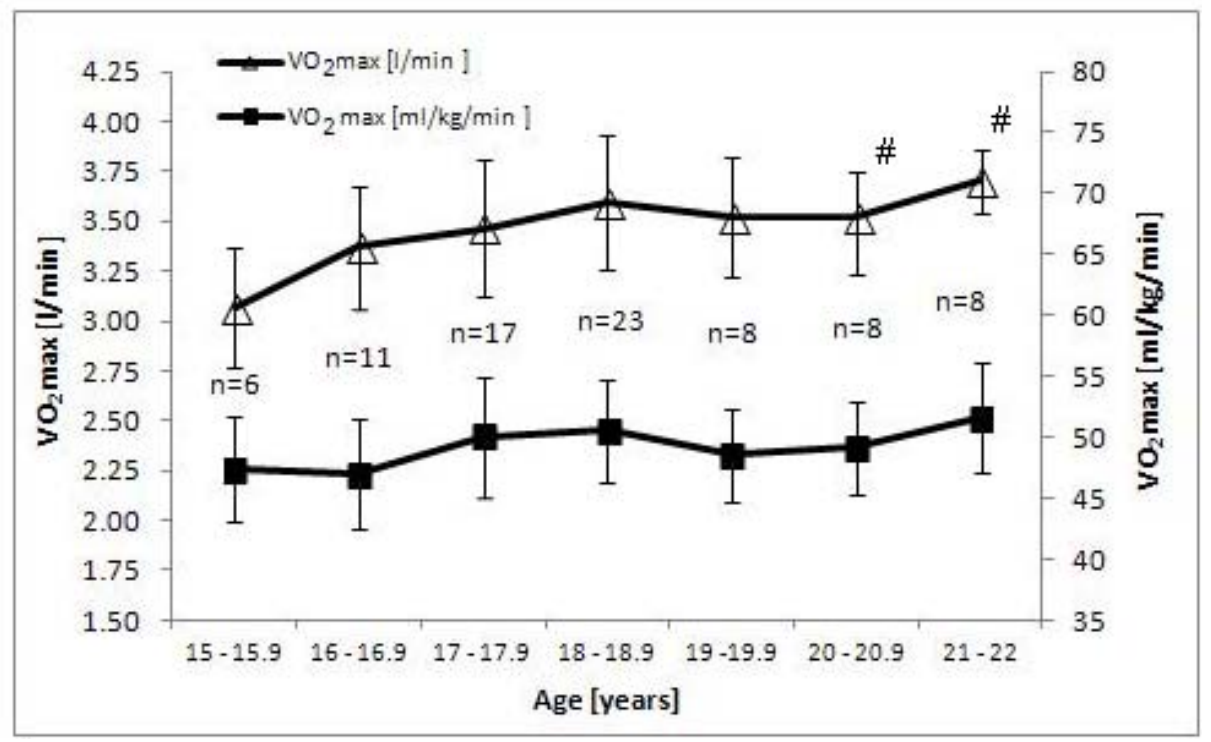

Figure 1

Maximal oxygen uptake $\left(\mathrm{VO}_{2 \max }\right)$ in the examined female rowers from various age groups $(n=81)$.

\# - significantly different from the 15-years old level $(p<0.05)$

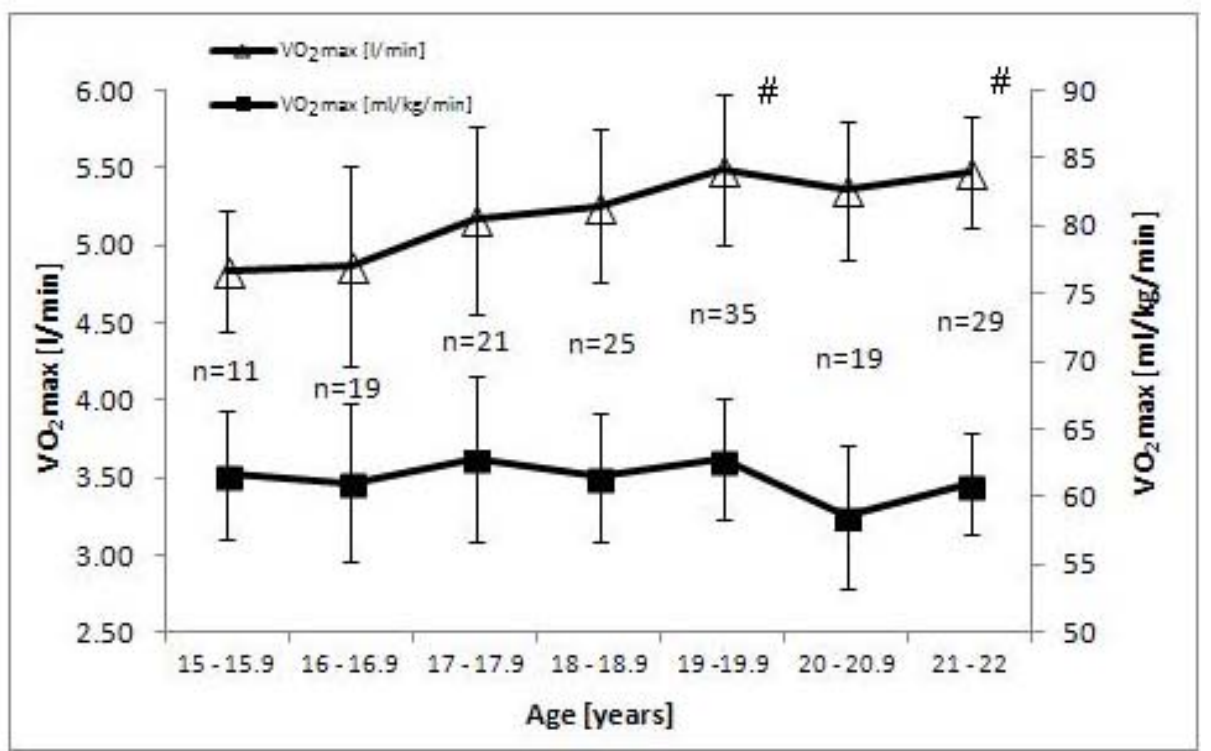

Figure 2

Maximal oxygen uptake $\left(\mathrm{VO}_{2 \max }\right)$ in the examined male rowers from various age groups $(n=159)$.

\# - significantly different from the 15-years old level $(p<0.05)$ 


\section{Results}

The reference values for maximal oxygen uptake (Table 2) are based on the results obtained during the exercise test in numerous groups of female and male rowers (sub-juniors, juniors, and U23) recruited from the Polish athletes of a different sports level.

The analysis of changes in the maximal oxygen uptake with age (expressed in $1 / \mathrm{min}$ ) showed significantly higher scores of the factor than the starting rate (age 15-15.9) only in senior female rowers (age 20-20.9 and 21-22). In male rowers substantial improvement was observed at the age of 19-19.9 and 21-22. Interestingly, maximal oxygen uptake in the context of body mass did not show significant changes within the age range from 15 to 22 neither in female nor in male athletes.

\section{Discussion}

The main goal of the present study was to quantify maximal oxygen uptake in rowers from different age categories and competition levels. The calculated reference values for elite Polish junior and U23 rowers allowed to evaluate the athletes' fitness level against the respective reference group and may aid the coach in controlling the training process (Table 2). Moreover, the data obtained from studies carried out over the last four years in elite Polish crews, medallists at the Olympic Games and World Championships, indicate that oxygen uptake of top female and male rowers markedly exceeds 4.0 and $6.0 \mathrm{l} / \mathrm{min}$, respectively. In lightweight athletes this uptake, expressed in relative units, exceeded $70 \mathrm{ml} / \mathrm{kg} / \mathrm{min}$ (Table 3). Other authors demonstrated that a male rower, a winner of numerous medals at the Olympic Games and World Championships, attained VO2max of $6.26 \pm 0.051 / \mathrm{min}$ (Lacour et al., 2009), whereas the mean value obtained for world elite quadruple scull rowers was $6.62 \mathrm{l} / \mathrm{min}$ (the highest individual value was $6.97 \mathrm{l} / \mathrm{min}$ ) (Mikulic, 2011). As indicated by a number of reports from studies of female and male rowers (Klusiewicz et al., 1999; Lacour et al., 2009; Mejuto et al., 2012; Secher et al., 1982) maximal oxygen uptake is of high diagnostic value when it is expressed in absolute values $(1 / \mathrm{min})$ or - in case of lightweight athletes whose body mass is strictly regulated and stable in relative values $(\mathrm{ml} / \mathrm{kg} / \mathrm{min})$.
In practical terms, it was important to evaluate a trend in the development of maximal oxygen uptake to get insight into the degree of improvement of the examined index in rowers. Such an analysis was based on studies carried out in Polish rowers and the results are plotted in Figures 1 (for females) and 2 (for males). Crosssectional data available for these athletes demonstrate that the highest significant increases in absolute values of $\mathrm{VO} 2 \mathrm{max}$ were recorded for 20-22-year-old females and the 19-19.9 and 21-22year-old males. Analysis of the data expressed in relative values hardly changed the trend described above for female rowers, while a marked decrease of the peak oxygen uptake was recorded in male rowers older than 19 years (statistically non significant). Taking into account the dynamics of annual changes, longitudinal studies of successful Croatian quadruple scull rowers demonstrated the highest improvement (by $6.8 \%$ ) of maximal oxygen uptake expressed in absolute values at the age of 19.2-20.2 years. Stabilization of the values of this index was detected at the age of about 20 years (Mikulic, 2011). In the Croatian rowers, the total "trainability" of VO2max over the five-year period equalled to $25.9 \%$, whereas during the seven-year observation of Polish rowers it amounted to 22.0 and $11.7 \%$ in females and males, respectively.

Other authors reported that in top rowers VO2max peaked at the age of 23 years and then slightly increased until 28 years of age (Messonier et al., 1998). A similar tendency was observed in elite runners above the age of 20-22 years (Legaz Arrese et al., 2005). Likewise, Lacour et al. (2009) based on the published data described the agerelated decrease (beginning from 20-25 years) in physical fitness and $\mathrm{VO} 2 \mathrm{max}$ in long-distance runners and swimmers. Murase et al. (1981) in their studies observed in the elite junior runners an increase in $\mathrm{VO} 2 \mathrm{max}$ from $3.54 \mathrm{l} / \mathrm{min}(65.4$ $\mathrm{ml} / \mathrm{kg} / \mathrm{min})$ to $4.49 \mathrm{l} / \mathrm{min} \quad(75.5 \mathrm{ml} / \mathrm{kg} / \mathrm{min})$ between the age of 14.8 and 18.8. Similarly, Rusko (1992) noticed that maximum oxygen uptake values improved with training in cross country skiers from approximately 55-60 to $75-80$ $\mathrm{ml} / \mathrm{kg} / \mathrm{min}$ between the age of 15 and 25 . On the other hand Ingjer (1992) observed a development in $\mathrm{VO} 2 \mathrm{max}$ in $\mathrm{ml} / \mathrm{kg} / \mathrm{min}$ only till $15-16$ th year of age, however, maximal oxygen uptake (expressed 
in $1 / \mathrm{min}$ ) in the tested leading Scandinavian skiers continued to improve until the age of 20. In this context, the results reported by Lacour et al. (2009) for an outstanding senior rower whose maximal oxygen uptake continued elevating until 32 years of age are quite exceptional.

The results of the research on the "trainability" of maximal oxygen uptake may lead to a conclusion that the growth rate of this index is larger in case of high-level athletes and that it

(in absolute values) increases significantly between the age of 19-22 years (U23 category).

\section{Acknowledgements}

This work was financially supported by the Polish Ministry of Sport and Tourism (Grant No. 2013.053/40/BP/DWM). The authors are grateful to the Regional Centre for Research and Development (ROBiR) in Biala Podlaska, for making available its scientific equipment to perform the measurements reported in the paper.

\section{References}

Hue O, Le Gallais D, Chollet D, Préfaut C. Ventilatory threshold and maximal oxygen uptake in present triathletes. Can J Appl Physiol, 2000; 25: 102-13

Ingjer F. Development of maximal oxygen uptake in young elite male cross-country skiers: a longitudinal study. J Sports Sci, 1992; 10: 49-63

Klusiewicz A, Faff J, Zdanowicz R. Diagnostic value of indices derived from specific laboratory tests for rowers. Biol Sport, 1999; 16: 39-50

Klusiewicz A. Relationship between the anaerobic threshold and the maximal lactate steady state in male and female rowers. Biol. Sport, 2005; 22: 171-180

Lacour J-R, Messonnier L, Bourdin M. Physiological correlates of performance. Case study of a world-class rower. Eur J Appl Physiol, 2009; 106: 407-413

Legaz Arrese A, Serrano Ostáriz E, Jcasajús Mallén JA, Munguia Izquierdo D. The changes in running performance and maximal oxygen uptake after long-term training in elite athletes. J Sports Med Phys. Fitness, 2005; 45: 435-440

Legaz-Arresea A, Munguía-Izquierdoa D, Nuviala Nuvialaa A, Serveto-Galindob O, Moliner Urdialesa D, Reverter Masía J. Average $\mathrm{VO}_{2 \max }$ as a function of running performances on different distances. Sci Sports, 2007; 22: 43-49

Losnegard T, Hallén J. Physiological differences between sprint- and distance-specialized cross-country skiers. Int J Sports Physiol Perform, 2014; 9: 25-31

Mejuto G, Arratibel I, Cámara J, Puente A, Iturriaga G, Calleja-González J. The effect of a 6-week individual anaerobic thereshold based programme in a traditional rowing crew. Biol Sport, 2012; 29: 297-301

Messonnier L, Bourdin M, Lacour J-R. Influence of age on different determining factors of performance on rowing ergometer. Sci Sports, 1998; 13: 293-294

Mikulic P. Maturation to elite status: a six-year physiological case study of a world champion rowing crew. Eur J App Physiol, 2011; 111: 2363-2368

Millet GP, Dréano P, Bentley DJ. Physiological characteristics of elite short- and long-distance triathletes. Eur J Appl Physiol, 2003; 88: 427-30 
Murase Y, Kobayashi K, Kamei S, Matsui H. Longitudinal study of aerobic power in superior junior athletes. Med Sci Sports Exerc, 1981; 13: 180-4

Rusko HK. Development of aerobic power in relation to age and training in cross-country skiers. Med Sci Sports Exerc, 1992; 24: 1040-7

Secher NH, Vaage O, Jackson RC. Rowing performance and maximal aerobic power of oarsmen. Scand J Sports Sci, 1982; 4: 9-11

Suriano R, Bishop D. Physiological attributes of triathletes. J Sci Med Sport, 2010; 13: 340-7

Yagüe PL, Del Valle ME, Egocheaga J, Linnamo V, Fernndez A. The competitive demands of elite male rink hockey. Biol Sport, 2013; 30: 195-199

\section{Corresponding author:}

\section{Andrzej Klusiewicz Ph.D}

Instytut Sportu

Trylogii 2/16, 01-982 Warszawa

E-mail: andrzej.klusiewicz@insp.waw.pl 